\title{
La población indígena y afrodescendiente de Paraná. Categorías socioétnicas entre 1755-1824
}

\section{Alejandro Richard"}

Fecha de recepción: 20 de noviembre de 2018. Fecha de aceptación: 3 de marzo de 2019

\begin{abstract}
Resumen
La actual ciudad de Paraná tuvo sus orígenes durante las primeras décadas del siglo XVIII, en el dinámico espacio de la frontera santafesina conocida como "la otra banda del Paraná". Los pobladores hispano-criollos, indígenas y afrodescendientes constituyeron la población del pequeño poblado que con el tiempo iría adquiriendo una mayor importancia económica y política. Con el objetivo de generar nueva información sobre la población indígena y afrodescendiente presente en la villa y ciudad de Paraná, durante la segunda mitad del siglo XVIII y primeras décadas del XIX, se llevan a cabo trabajos de archivo en torno a documentos eclesiásticos y el censo poblacional de Paraná del año 1824. Se discuten los contextos de aplicación de las diferentes categorías socio-étnicas utilizadas en los documentos, al tiempo que se analizan las características particulares de distintos sectores que componen la población paranaense.
\end{abstract}

The indigenous and afrodescendant population of Paraná. Socio-ethnic categories between 1755-1824

\begin{abstract}
The current city of Paraná had its origins during the first decades of the 18th century, in the dynamic space of the Santa Fe border known as "la otra banda del Paraná". The Spanish-Creole, Indigenous and Afro-descendant settlers constituted the population of the small town that would acquire greater economic and political importance over time. Aiming at generating new information about the Indigenous and Afro-descendant population present in the town and city of Paraná during the second half of the 18th century and the first decades of the 19th century, archival work is carried out around ecclesiastical documents and the population census of Paraná of 1824. The
\end{abstract}

Palabras clave

Paraná

Etnohistoria

Diáspora africana
Key-words

Paraná

Ethnohistory

African diaspora

* Consejo Nacional de Investigaciones Científicas y Técnicas (CONICET), Centro de Arqueología Urbana, IAA-UBA. Museo Prof. Antonio Serrano, Paraná. La Plata, Argentina. E-mail ale_rich37@hotmail.com 
1. Los trabajos descriptos se enmarcan en un proyecto de Beca Doctoral del CONICET que plantea la necesidad de generar nueva información desde la Arqueología Histórica en torno a los grupos indígenas y afrodescendientes que conformaron la sociedad paranaense desde sus inicios hasta el siglo XIX. Como una primera aproximación al conocimiento de aquellos sectores sociales que nos brinde las bases interpretativas al momento de proyectar y realizar excavaciones arqueológicas dentro del casco urbano paranaense, nos remitimos a las fuentes históricas disponibles a fin de disponer de información cuantitativa y cualitativa sobre el conjunto poblacional, a partir de una lectura crítica de ellas. contexts of application of the different socio-ethnic categories used in the documents are discussed, as well as the particular characteristics of the different sectors that make up the population of Paraná are analyzed.

\section{Introducción}

El hecho de que los inicios del poblado de Paraná partieran de la instalación de un fuerte y la erección de una capilla en sus inmediaciones (Pérez Colman, 1937; Sors, 1981) dio origen a que el relato historiográfico tradicional se haya edificado sobre algunos preceptos: el rol pionero y cimentador de la Iglesia para la sociedad paranaense, en particular, y entrerriana, en general, y la mínima o inexistente presencia de los sectores indígenas, afrodescendientes y afromestizos en el seno de aquella sociedad, sobre todo para momentos posteriores a las campañas punitivas contra los charrúas desarrolladas a mediados del siglo XVIII (Sallaberry, 1926; Djenderedjian, 2008). ${ }^{1}$

En este trabajo se analizan los libros de Bautismos y Matrimonios de la Parroquia de la Bajada del Paraná entre 1755 -momento en que se comenzó a registrar a la feligresía- y 1799, y el censo poblacional de 1824, donde se consideraron diversos elementos sobre cada habitante empadronado -edad, patria, color, ocupación, condición en la unidad censal. A partir de esto indagamos sobre las características propias de cada conjunto étnico que compone la sociedad paranaense, muy relacionada a la vecina ciudad de Santa Fe.

Las diferentes categorías, tanto referentes a indígenas como a afrodescendientes y afromestizos, grafican la variedad étnica existente en el área estudiada, como también las percepciones que de ella tienen quienes producen los documentos estudiados. Se destaca la referencia a indígenas guaraníes-misioneros, charrúas -incluso décadas después de su "exterminio"--, y personas procedentes de encomiendas donde confluyeron sucesivamente indígenas de diversos grupos étnicos regionales. Aunque las actas matrimoniales reflejan procesos de mestizaje afro-indígena ocurridos desde las primeras décadas en que se tiene registro -a partir de lo cual se generalizará la utilización de la categoría "pardo"- será la migración de pobladores afromestizos provenientes de Santa Fe la que contribuirá en mayor medida al crecimiento porcentual de este sector, que para 1824 representaba el 17\% de la población empadronada.

Se busca problematizar las categorías socioétnicas utilizadas para clasificar a los habitantes, valiéndonos de algunas historias de vida que ejemplifican el carácter dinámico y subjetivo de aquellas clasificaciones.

\section{La presencia de africanos y afrodescendientes esclavizados y libres en la bajada del Paraná y alrededores}

La región donde se emplaza actualmente la ciudad de Paraná ha sido testigo de complejos y dinámicos procesos interétnicos desde la fundación de la ciudad de Santa Fe la Vieja hacia fines del siglo XVI. El gobierno colonial comenzó desde entonces a estructurar el territorio en torno a la nueva ciudad (Cervera, 1982; Carrara, 1998; Barriera, 2013), y tempranamente se establecieron diversas estancias en los terrenos de "la otra banda" del Paraná (Pérez Colman, 1937). A partir del siglo XVII las relaciones entre los santafesinos y los grupos indígenas locales se convirtieron en articuladoras de la vida económica y social en torno a aquellas estancias (Pérez Colman, 1937; Areces et al., 1992). Un claro 
ejemplo de estas interacciones es el caso de los grupos pertenecientes al linaje del cacique Yasú, asentados en la zona de la Bajada y muy ligados al Cabildo santafesino (Sallaberry, 1926; Cervera, 1982; Harman, 2010). Cabe destacar, como señalan Latini y Lucaioli (Latini, 2012; Latini y Lucaioli, 2014), que la región de la banda oriental del río Paraná, junto con los terrenos ubicados al norte de la mudada Santa Fe, constituyeron un complejo fronterizo dinámico donde las interacciones políticas y económicas entre los grupos indígenas y los agentes coloniales fueron variando con el tiempo y las circunstancias.

La referencia más temprana a esclavizados en "la otra banda" del Paraná de la cual disponemos, data de un documento en que se relatan sucesos acontecidos en la primera Estancia San Miguel que la Compañía de Jesús administró sobre estas tierras, ${ }^{2}$ en terrenos ubicados al sur del Arroyo Las Conchas, entre 1664 y 1679, cuando finalmente trocó las tierras en un convenio con descendientes de Garay y Hernandarias (Pérez Colman, 1937; Calvo, 1993). En aquella ocasión, el Padre Valaguer elevó una petición al Cabildo pidiendo permisos para realizar una vaquería, alegando que "por acciones del tiempo, muerte de esclavos, y gente de nuestro servicio" el ganado que allí tenía la Compañía se retiró tierra adentro (Richard, 2015).

A partir del traslado de la ciudad de Santa Fe hacia su localización actual a mediados del siglo XVII, las relaciones entre los indígenas -y demás pobladores de la Bajada- y los santafesinos se incrementaron. En 1726 se trasladaron algunas familias santafesinas al vecino paraje, y en 1727 se dispone construir allí un fuerte (Pérez Colman, 1937). De este modo, sin constar una fundación oficial con el transcurrir de los años la Bajada del Paraná se consolidó como centro poblado con la erección de la Parroquia en 1730 y la institución de la Alcaldía de la Hermandad (Pérez Colman, 1946; Fasolino, 1960; Sors, 1981; Ceruti, 2007).

Continuando con las referencias a africanos y afrodescendientes en sus inmediaciones encontramos que en 1732 los abipones pasaron a la otra banda del Paraná y derrotaron a las fuerzas locales al mando del Sargento Mayor Martín de Sandoval, ${ }^{3}$ como resultado se cuentan trece bajas entre sus tropas, y uno de los caídos es "el esclavo Laureano Gaete" (Pérez Colman, 1937). En aquel contexto, en 1738, ante conflictos con parcialidades charrúas, el cabildo santafesino dispone el traslado a la otra banda del Teniente de Gobernador Francisco Echagüe y Andía "a fin de requerir y amonestar a los dichos indios, sobre que vivan y se porten con toda buena correspondencia con los españoles y cristianos, aunque sean indios y negros" (Sallaberry, 1926).

Un fragmento del diario del Capitán Francisco de Aguirre que ya ha sido citado por otros investigadores relata que hacia 1784 :
A principios de este siglo pasaron los tres primeros vecinos de Coronda afligidos de la persecución de los Abipones, a poco pasaron sus ganaditos y uno después de otro se situaron donde les pareció mejor. Por el año 1740 ya tenían capilla, cuyos primeros ranchos alrededor fueron de unos pardos (Aguirre 1951, en Ceruti, 2007: 389).

En el año 1788, la media legua cuadrada donde se estableció el primer caserío fue donada a la Parroquia por doña María Francisca Arias de Cabrera y Saavedra, lo cual conllevó cierto progreso ya que muchas personas se asentaron en aquellos terrenos. Los africanos y afrodescendientes se fueron instalando en las cercanías de la ribera, hacia la margen norte del antiguo poblado. 2. DEEC. EC, Tomo 57, Exp. 98, f.
329v.

3. AGPSF. Actas Capitulares, tomo $X$, f. 114-115v. 
Aquel caserío tomó tal importancia que allí se erigió el segundo edificio religioso de la villa, hacia 1822: la capilla de San Miguel Arcángel (Schávelzon, 2003, 2017; Ceruti, 2007). Como expresa Pérez Colman (1946: 60) la población que vivía en estos parajes "estaba compuesta por morenos, en buena parte esclavos, que durante los sábados por la noche celebraban sus danzas africanas conservadas por tradición", dando origen a que el barrio se conozca como el barrio del tambor.

\section{Clasificaciones por color y categorías socio-étnicas}

Para analizar las categorías socioétnicas implementadas en las distintas fuentes consultadas es necesario hacer un paréntesis e individualizar los elementos que se encuentran en juego. Las diversas personas apuntadas recibieron etiquetas subjetivas sobre si su color o condición se correspondía, por ejemplo, a la de un "indio" o la de un "pardo". Contamos con estudios que se abocan a analizar las clasificaciones por color y sus dinámicas particulares para la Santa Fe pos-revolucionaria y la vecina región del Tucumán colonial y pos-colonial como los de Guzmán (1999, 2011, 2013, 2016); Boixadós y Farberman (2009); Candioti (2016) y Farberman (2016).

Siguiendo a Boixadós y Farberman (2009), sostenemos la idea de que estas clasificaciones no eran caprichosas sino que respondían a determinados criterios que limitaban la ambigüedad clasificatoria, tales como: 1) los criterios de origen jurídico, donde la condición de "indio encomendado" o de "esclavo" fue más relevante que la asociación étnica o de origen del sujeto en cuestión; 2) la memoria del origen de los antepasados del sujeto clasificado, lo cual estaba estrechamente ligado al conocimiento que tuviera de su historia familiar el empadronador o cura; 3) las características fenotípicas, así como su vestimenta e idioma; 4) el componente "relacional", que estaría dando origen, por ejemplo, a que en los padrones se anotaran casi exclusivamente matrimonios entre iguales socioétnicos, o se homologaran las categorías de los habitantes de una vivienda a la de la persona "cabeza de familia"; y 5) el orden de llegada donde, según lo observado por las investigadoras, la antigüedad de algunos pobladores en la zona, o el rol de su familia en el proceso colonizador podrían estar valiéndoles a unos y otros el mote de "español".

A partir del estudio de diferentes fuentes documentales observamos que, a lo largo del tiempo y dependiendo de la naturaleza del documento y de quién los completa, unos criterios clasificadores tendrán mayor relevancia por sobre otros. Mientras que en las actas bautismales juegan un papel importante los criterios de origen jurídico, en las actas matrimoniales se articulan criterios jurídicos con aquellos ligados a la memoria de origen y las características fenotípicas de las personas involucradas. En el censo de 1824 parecieran pesar los criterios fenotípicos y relacionales, lo cual puede deberse, en parte, a la reciente llegada del cura Francisco Álvarez a la región y su consecuente desconocimiento de elementos ligados al linaje y las historias familiares de los sujetos empadronados.

En cuanto a este censo, cabe destacar que nos sitúa en las primeras décadas pos-revolucionarias donde las categorías heredadas de los sistemas clasificatorios coloniales se vieron modificadas ante el nuevo contexto social y político. Para comenzar a dimensionar el carácter situacional y dinámico de aquellas categorías resulta interesante analizar, en primera instancia, el cambio de paradigma ocurrido entre la colonia temprana y tardía. Hacia el siglo XVI, 
"raza" remitía a un concepto nobiliario, de linaje y de uso corporativo no restringido exclusivamente al fenotipo, mientras que durante el siglo XVIII aquella concepción fue modificándose y el color tomó mayor relevancia en la definición de los rasgos morales y la "calidad" de las personas. De este modo, el esquema de las dos repúblicas, desbordado por los intercambios fenotípicos que pretendía contener, dio lugar a lo que la historiografía llamó el "sistema de castas". Allí los grupos socioétnicos-raciales poseerán estatus diferenciados y una conciencia ligada a su ascendencia mezclada o no, visible por el fenotipo (Guzmán, 2013; Farberman, 2016).

Las "castas" se configuraron en subcategorías que designaban a los sujetos mezclados: mestizo, zambo, mulato, pardo, moreno, etc. Las diferentes taxonomías hacían referencia, a grandes rasgos, a la "calidad" de las personas clasificadas, teniendo en cuenta no solo los elementos fenotípicos sino también su ocupación, lenguaje, vestimenta, y lugar de residencia (Guzmán, 2013). Estas categorías necesitan ser problematizadas en la medida en que no están reflejando entidades reales y objetivas sino construcciones intelectuales de los empadronadores (Boixadós y Farberman, 2009).

Estamos hablando de categorías subjetivas y altamente dinámicas, que se reflejan de diversas maneras en los diferentes documentos históricos. Las investigaciones arriba citadas, de Boixadós, Farberman y Guzmán, dan cuenta de casos en que estas categorías variaban al momento de clasificar a los mismos sujetos ante diferentes circunstancias. Mientras que en los documentos jurídicos entra en juego la auto-referenciación y el contexto legal en que la persona se presenta ante las autoridades, en los padrones son determinantes tanto el conocimiento que tiene el empadronador de la población, como las relaciones personales entre los actores involucrados.

En el censo de 1824, se utilizaron solamente cuatro categorías para clasificar a la población entre blancos, indios, pardos y negros. De este modo, se implementó el término "pardo" para referir a las castas del período colonial. Aunque Farberman (2016) observa que para la provincia de La Rioja, en tiempos revolucionarios, el término "pardo libre" se constituyó en una forma políticamente correcta de expresar a las antiguas castas, en nuestro caso paranaense observamos que el uso de aquella categoría ya estaría muy difundido entre la curia durante el siglo XVIII.

¿De qué manera se refleja en el padrón estudiado el mestizaje, en tanto configuración que pone en contacto a individuos pertenecientes a categorías étnicas diferentes (Guzmán, 2016)? Para intentar responder esta pregunta ponemos bajo la lupa algunos casos particulares ¿Cómo clasificó el censista a los hijos de parejas "mixtas"? En el padrón se observa la siguiente tendencia ya apuntada por Reina (1973): ante la unión de Indio y Blanca, hijos blancos; Pardo e India, hijos indios; Pardo y Blanca, hijos blancos; Indio y Parda: hijos pardos; Blanco e India, hijos blancos; Indio y Blanca, hijos blancos. En cambio, para Blancos y Pardas, los hijos pueden ser clasificados tanto blancos como pardos.

Se destacan algunos casos de madres viudas o solteras, o donde el padre de familia se encuentra fuera del hogar, en que la categoría asignada a la descendencia no se condice con la de la madre. Esto abre la interpretación a pensar en la posibilidad de que Álvarez haya clasificado a las personas por sus características fenotípicas, quizás desconociendo o restando importancia a su ascendencia. El análisis del siguiente ejemplo resulta interesante: 
-Agueda Quixano, 26 años, casada, india.

(Hijo) José Gregorio Quixano, 12 años, soltero, blanco.

(Hija) María Mercedes Quixano, 1 mes, blanca.

-(Hermana) Maria Luisa Quixano, 36 años, viuda, parda.

(Hija) Paloma Ríos, 20 años, soltera, parda.

(Hija) Fernanda Ríos, 15 años, soltera, parda.

(Hijo) Fernando Ríos, 12 años, soltero, pardo.

(Hijo) Tomas Ríos, 11 años, soltero, pardo.

En este caso, podríamos suponer que entre la ascendencia de las hermanas Agueda y María Luisa se encuentran tanto indígenas como afrodescendientes, y que el empadronador refirió puntualmente a los rasgos fenotípicos de una y otra para mencionarlas respectivamente como "india" y "parda". A su vez, el padre de los hijos de Agueda podría ser una persona "blanca", por lo que sus hijos entraron en aquella categoría. No ocurrió lo mismo con la descendencia de María Luisa, cuyos hijos fueron catalogados, al igual que ella, como pardos.

\section{Los fondos eclesiásticos}

En la capilla de Paraná se comenzaron a completar libros de bautismos en 1755 y de matrimonios en 1764, con la particularidad de que no se contemplaron libros diferenciados para "españoles" e "indios y castas". Desde esos momentos, diversos curas se hicieron cargo de la capilla y fueron anotando los sacramentos y matrimonios prestando atención a distintos detalles en torno a los feligreses involucrados. En el presente trabajo se analizan las actas correspondientes al período $1755-1800$.

Los documentos eclesiásticos reflejan la presencia de indígenas de distintas etnias y afrodescendientes libres y esclavizados desde que se comenzó a tener registros, hacia mediados del siglo XVIII. En términos generales observamos que los distintos religiosos que completaron los libros de bautismos y matrimonios utilizaron las categorías "indio", "pardo" y "negro", con excepción del padre Joachin Sotelo quién utilizó, además, las denominaciones "moreno" y "mestizo" entre 1755 y 1761, y del cura José Martiniano Alonso quien también usó la categoría "mulato" durante las dos últimas décadas del siglo XVIII. Si seguimos analizando a vuelo de pájaro las categorías empleadas, observamos que la de "indio" irá acompañada de la adscripción étnica -por ejemplo, india charrúa- o la procedencia de estas personas -es decir, de qué encomienda, pueblo o reducción proceden-, mientras que sólo el mencionado Sotelo utilizó el término "indio libre" o "india mestiza" en contadas oportunidades durante los años referidos. En cuanto al conjunto afrodescendiente se observa que la categoría de color irá acompañada generalmente de la condición jurídica de las personas consideradas. De este modo se emplean, por ejemplo, los términos "pardo libre", "esclavo", "negra libre" y "sirviente". Este último, a su vez, es utilizado en menor medida para indígenas que se encuentran bajo el régimen de servicio personal, aclarando en cada caso "indio sirviente de la casa de...".

AAP. Nuestra Señora del Rosario, Paraná, Bautismos, Libro 1.

6. Teresa Suarez identifica un $17 \%$ de ilegitimidad en Santa Fe para el período 1680-1780 (Suarez, 1992), mientras se observan valores de $14,89 \%$ en Baradero entre 1756 1765 (Salas, 2012) y de $24 \%$ y $31 \%$ en Buenos Aires y Corrientes respectivamente, entre 1800-1825 (Guzmán, 1997; Valenzuela, 2016).
En cuanto a la ilegitimidad registrada entre los bautismos, identificamos un aproximado $^{4}$ de $11,37 \%$ de nacimientos ilegítimos para el período $1755-1764 .{ }^{5}$ Este porcentaje, menor a lo observado para otras localidades de la región platina, ${ }^{6}$ podría deberse a que muchos nacimientos ilegítimos no pasaron por la iglesia. De ser así, esto nos llevaría a plantearnos cuál era el rol y alcance real de esta institución durante los inicios del poblado de la Bajada. Consideramos 
que para sostener esta hipótesis hacen falta comparaciones con períodos locales más tardíos y sus correlativos contextos políticos y sociales.

¿Quiénes son los "indios" apuntados en los documentos? Al estar acompañada de una adscripción étnica o una procedencia, esta categoría permite entrever los diferentes contextos en que fue implementada:

A) "India charrúa": a partir de 1755 -cuando comienzan a registrarse bautismos- observamos que se realizan diversos bautismos tanto de indias charrúas adultas, como de hijos e hijas de madres charrúas que se encontraban al servicio de diversos vecinos. ${ }^{7}$ El hecho de que todos los casos que se refieren a la etnia charrúa se encuentren registrados hasta 1761, y que todas las personas a quienes se les asignó esa categoría sean mujeres, se encuentra íntimamente relacionado a los procesos represivos que se desarrollaron a partir de las campañas punitivas, llevadas a cabo principalmente entre 1749 y 1752, contra el pueblo charrúa. Desde aquel año, las fuerzas coaligadas de Santa Fe y Buenos Aires desarrollaron sucesivas entradas a tierras entrerrianas con la orden de pasar a degüello a todo charrúa mayor de doce años que no se rindiera. Los 339 prisioneros y prisioneras fueron trasladados hasta el río Salado, donde se fundó en 1750 la reducción de Nuestra Señora de la Concepción de Cayastá, mientras que otros cautivos fueron repartidos entre los santafesinos como servidumbre (Sallaberry, 1926; Pérez Colman, 1930; Cervera, 1982; Lucaioli y Latini, 2014; Lucaioli, 2015).

Se encuentran, a su vez, algunas referencias a indígenas cautivas de los charrúas, ${ }^{8}$ que podemos relacionar tanto a las acciones punitivas de mediados del siglo como a los "rescates de indios" desarrollados en el contexto santafecino a lo largo del siglo XVII y parte del XVIII. ${ }^{9}$

B) "Indio guaraní": la presencia guaraní entre los pobladores de la Bajada se evidencia mediante distintos elementos como la utilización de la categoría "indio guaraní", la referencia a diversos orígenes jesuíticos -del Pueblo de Yapeyú, de La Cruz, San Borja o Mártires-, o simplemente por el registro de diferentes apellidos de origen guaranítico, ${ }^{10}$ como también observa Harman (2010) para Concepción del Uruguay. Esta presencia es el resultado de los procesos migratorios producidos desde los diversos pueblos misioneros, tanto en tiempos anteriores como posteriores a la expulsión de la Compañía de Jesús (Maeder y Bolsi, 1982).

C) "De la encomienda de Vera", tanto de "don Francisco de Vera" como de "don Joseph de Vera": gran parte de las menciones a indígenas entran en esta categoría, que se constituye en la excepción al momento de relacionar una referencia repetida en los documentos a alguna categoría étnica. La mención de "Don Francisco de Vera", presente hasta el año 1770, refiere al Teniente de Gobernador Francisco Antonio de Vera Mujica, y “Don Joseph de Vera” refiere a su hijo y sucesor José de Vera Mujica (Calvo, 2001). Diversos factores, como las características propias de la encomienda santafesina (Cervera, 1982; Areces y Tarragó, 1999; Calvo, 2004), la extensa historia de la familia Vera Mujica en Santa Fe (ver Areces y Tarragó, 2001; Calvo, 2001; Lucaioli, 2015) y su activa participación política en torno al complejo fronterizo santafesino (Lucaioli y Latini, 2014; Lucaioli, 2015), llevaron a que hacia la segunda mitad del siglo XVIII aquellas encomiendas estuvieran integradas por indígenas de diversos orígenes étnicos.
7. Como ejemplos: Antonia, india charrúa adulta al servicio de Pedro Salazar; María, india charrúa adulta al servicio de Joseph Cardozo; Miguel Gerónimo, hijo de padre no conocido y de María india charrúa de la casa de Joseph Portillo (AAP, Nuestra Señora del Rosario, Paraná, B 1, f. 8v, 9v y 42v).

8. Se bautizan tres indias cautivas de los charrúas que se encuentran en las casas de Blas Duré, Pascuala Altamirano y Juan Cardozo, en el año 1759 (AAP. Nuestra Señora del Rosario, Paraná, B 1, f. 29).

9. Los "rescates de indios", donde lisa y llanamente se intercambiaban cautivos y cautivas por mercadería entre vecinos santafesinos y grupos charrúas, se constituyeron en una estrategia adoptada tanto por las elites santafesinas como por las parcialidades charrúas y han sido analizados por diversos autores como Areces et al. (1992, 1999); Areces y Tarragó (1999); Cervera (1982); Lucaioli (2015); Richard (2015).

10. Como ejemplos Guapayú, Arasay, Guariyú,Cuñaeté, Arupa, Eguatí. 
Las referencias descriptas operan como disparadores para preguntarnos ¿qué es un indio a los ojos de la curia de la Bajada del Paraná durante el período estudiado? y ¿qué rol cumplen los diferentes factores en juego a la hora de la conceptualización de las personas en cuestión?

Por un lado, es evidente que entran en juego elementos jurídicos que llevarán al cura a registrar a un individuo como "indio de la encomienda de...", ya que este tributa y mantiene una relación concreta con un determinado vecino hispano-criollo. Por el otro, se observa que en aquella caracterización entran en juego otros elementos que hacen a la "calidad" de las personas, como la vestimenta, la ocupación y el idioma. Esto último se estaría evidenciando en tanto algunas personas de clara ascendencia guaraní -portadoras de apellidos guaraníes, o descendientes de madres con apellido guaraní- fueron registradas simplemente con su lugar de origen sin ser referidas como "indias".

En cuanto a los afrodescendientes libres y esclavizados, se han reconocido en las fuentes bautismales y matrimoniales a personas catalogadas como negros, pardos, mulatos y pardo/mulatos. Estas categorías se articulan con las de esclavos y sirvientes en los casos de personas esclavizadas, relacionándolas seguidamente a sus propietarios. En cuanto a los matrimonios donde se vieron implicados afrodescendientes, en su mayoría se trataron de parejas mixtas afro-indígenas siendo reducido el número de matrimonios celebrados entre pardos o negros tanto libres como esclavizados.

\section{Los primeros censos poblacionales de la Bajada del Paraná}

Las primeras operaciones censales realizadas en el territorio de Paraná fueron relevamientos de los pobladores de la campaña: en 1745, por cuestiones tributarias se mandó a empadronar a los pobladores de los campos situados en proximidades de la Bajada (Pérez Colman, 1937). A comienzos del siguiente siglo, durante el año 1803, las autoridades eclesiásticas llevaron a cabo un censo de su feligresía: ${ }^{11}$ la nómina de feligreses del curato de Paraná, sin embargo, comprendió exclusivamente a los habitantes de la campaña. No sabemos si esto fue intencional o se debió al extravío de la nómina correspondiente al pueblo (Pérez Colman, 1937).

El censo impulsado en 1820 por Ramírez, en todo el territorio de la proyectada República de Entre Ríos, se constituye en el primero realizado por las autoridades gubernativas. En este censo, cuyo original se encuentra en el Archivo General de la Provincia de Corrientes, los censistas apuntan, diferenciando hogar por hogar, nombres y apellidos, profesión, estado civil y edad de los habitantes. Siguiendo a Pérez Colman (1946) en lo que respecta a Paraná, en él se registran 781 casas, 4292 habitantes y 221 esclavos.

\section{El censo de 1824}

12. Conservado en AGPER. Fondo de Gobierno, Serie VII, Leg. 2.

En 1824 se dispuso la realización de un nuevo censo, ${ }^{12}$ el cual sería llevado a cabo por los curas párrocos locales. En Paraná, el censista fue el cura Francisco Dionisio Álvarez. Los autores que han trabajado hasta el momento con este documento registraron totales poblacionales levemente dispares: siguiendo a Pérez Colman (1946) la población de Paraná constaba de 3726 habitantes y 28 esclavizados, mientras que Reina (1973) refiere un total de 3643 habitantes. 
El padrón detalla nombre, patria, edad, estado, color y profesión de cada habitante. En la categoría "color", el censista utilizó las categorías "negro/negra", "indio-india", "blanco-blanca" y "pardo-parda".

Si bien Pérez Colman (1946) apunta que la designación de un cura local como censista puede haber respondido a su frecuente conocimiento de la feligresía, en el caso del censo de 1824 esto es relativo, ya que Álvarez no llevaba más de dos años en la ciudad al momento de su ejecución. Es probable, por lo tanto, que tuviera un conocimiento parcial de las personas empadronadas y de sus historias familiares. ${ }^{13}$

Los datos que brinda el censo de 1824 ya fueron expuestos en detalle por Pérez Colman (1946) y Reina (1973), por lo que en los párrafos siguientes nos limitaremos a mencionar algunas particularidades que aportan a la interpretación de la dinámica social analizada en el presente trabajo.

Se identificó un total de 3654 habitantes, ${ }^{14}$ de los cuales 1708 son nacidos en Paraná y de los restantes 1946, 1021 habitantes son nacidos en Santa Fe. Es decir que sólo el 46,85\% de la población es de origen local, mientras que se observa un estrecho vínculo con la vecina ciudad. Para 1809, la Bajada del Paraná registraba tan sólo 150 viviendas (Ceruti, 2002), mientras que once años más tarde se contabilizaron 781. Este crecimiento ocurrido durante las primeras décadas del siglo XIX puede estar relacionado, en parte, a la decadencia económica que atravesaba la ciudad de Santa Fe hacia fines del siglo XVIII y comienzos del XIX (Halperin Donghi, 1972; Candioti, 2016), y un consecuente flujo de personas desde allí hacia el vecino poblado.

Una pirámide poblacional del conjunto de habitantes (Figura 1) nos muestra una población joven, mediante una pirámide con forma expansiva (INDEC, 2018). Lo mismo se observa al proyectar una pirámide poblacional a partir de aquellas personas nacidas en Paraná (Figura 2). Los bajos valores observados en los rangos etarios masculinos, entre 10 y 49 años, pueden deberse al contexto bélico del momento estudiado. Destacamos que los valores menores observados en el sector masculino se acentúan entre quienes nacieron en Paraná.
13. El Padre Francisco Dionisio Álvarez, nacido en Buenos Aires en 1786, perteneció a la orden franciscana y obtuvo en 1820 la licencia pontifica para secularizarse. En diciembre de 1822 se trasladó a Paraná como Excusador del también porteño Antolín Gil y Obligado, quien se hallaba allí desde 1804 . Sobre la relevancia de los curas empadronadores y sus conocimientos en torno a la feligresía, ver Boixadós y Farberman (2009) y Faberman (2016).

14. Las cifras dispares publicadas por otros autores, como Pérez Colman (1946) y Reina (1973), podrían deberse al hecho de que en la última foja del documento se consignan algunas cifras a modo de "balance", donde se indica un total -reproducido por Pérez Colman- de 3726 habitantes, el cual no se condice con la suma persona por persona en el padrón.

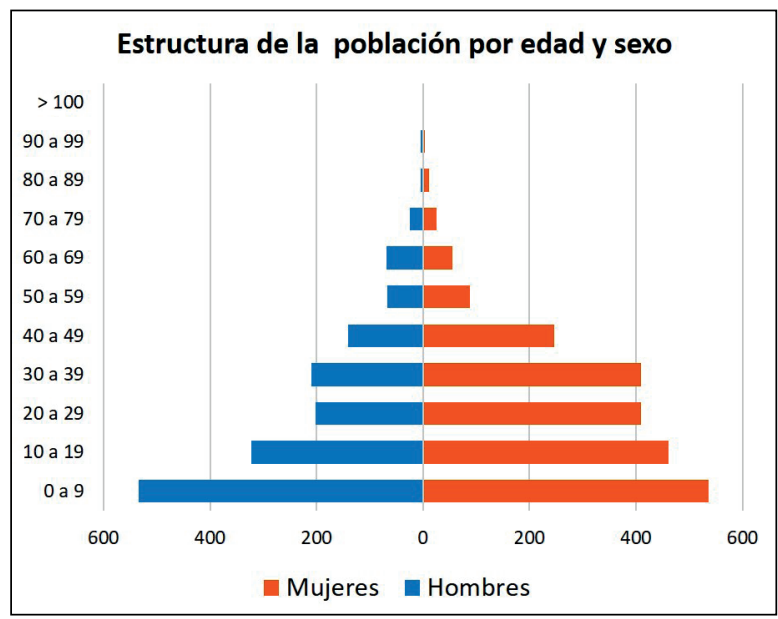

Figura 1. Pirámide demográfica del conjunto de la población según el censo de Paraná, año 1824.

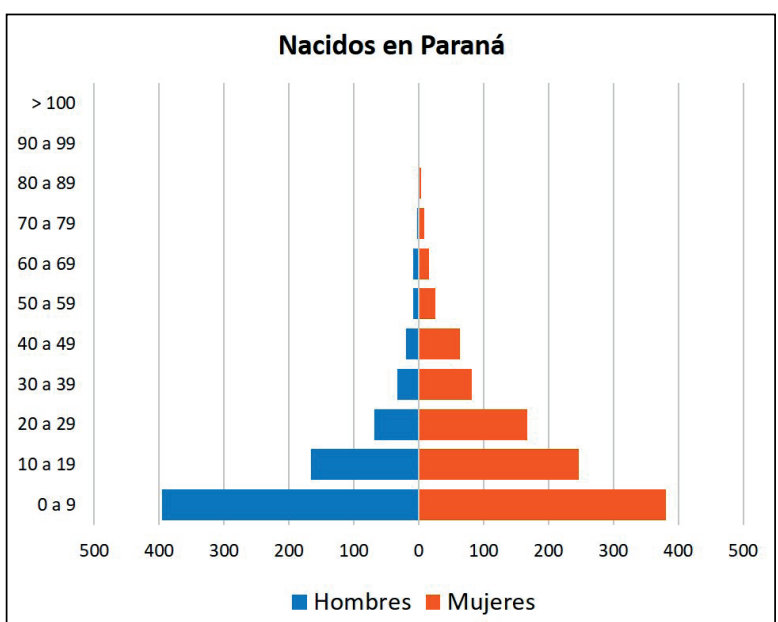

Figura 2. Pirámide demográfica de la población nacida en Paraná según censo de Paraná, año 1824. 
Las pirámides poblacionales resultantes de la diferenciación entre categorías de color contempladas en el padrón (Figura 3) permiten observar que, en principio, estarían operando diversos procesos y factores -tanto migratorios y laborales como de natalidad- entre los pobladores adscriptos a las diferentes categorías. Si bien entre ellas son una constante los valores menores en el sector masculino -sobre todo entre los 10 y 39 años-, destacamos algunas particularidades:

a) La estructura de la población negra presenta desproporciones que podrían estar relacionadas a factores laborales y migratorios asociados a la esclavitud y la diáspora africana, ya que por fuera del rango 10-29 años se observa una mayoría de hombres. Esta estructura podría deberse también a una menor esperanza de vida entre las mujeres, una alta mortalidad infantil o simplemente a una baja tasa de nacimientos como consecuencia lógica de la institución esclavista que hacia 1824 recién comenzaba a desvanecerse.

b) Una mayoría relativa de mujeres en las categorías indios y pardos, que podría deberse tanto al mencionado contexto bélico como a una preponderancia del trabajo doméstico en el entorno urbano al que estarían expuestos estos sectores de la sociedad, no observándose dicha mayoría entre la población categorizada como blanca.

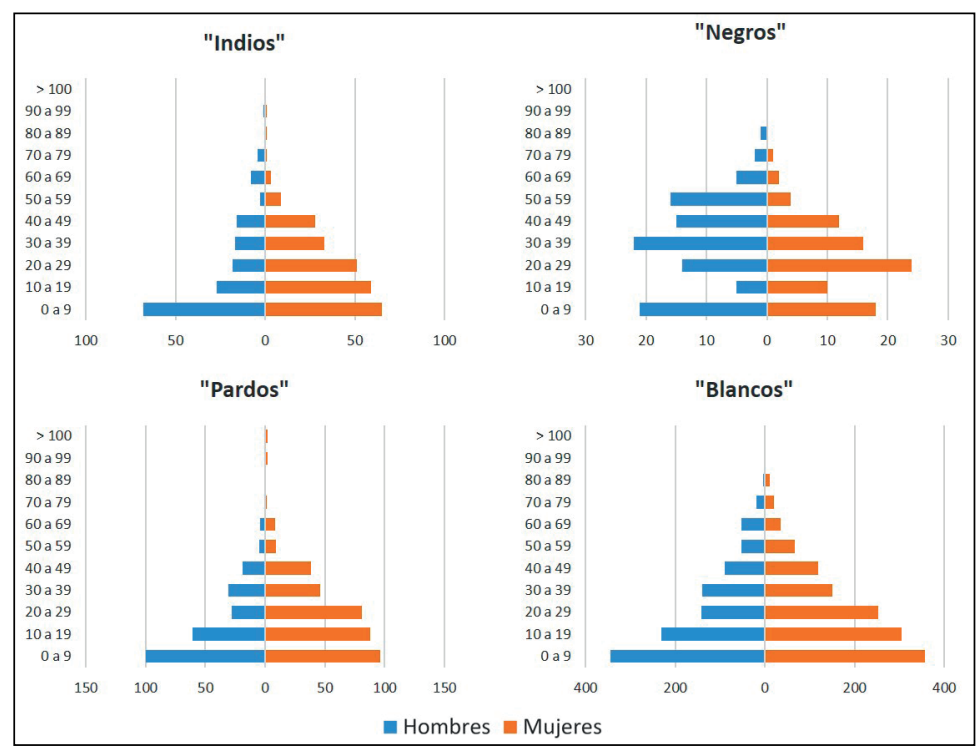

Figura 3. Pirámides poblacionales por categoría socio-étnica empleada en el censo de Paraná, año 1824.

En cuanto a las profesiones, ya detalladas por Reina (1973), se observan a grandes rasgos algunas particularidades en torno a lo que percibe el empadronador sobre quiénes poseen una u otra profesión: de los 50 comerciantes, a 43 se les otorga el "Don" antepuesto a sus nombres y ninguno de ellos es identificado como indio, pardo o negro. En cuanto a los 46 pulperos apuntados, ninguno es identificado en tanto indio, pardo o negro, mientras que a 37 de ellos se les otorga el "Don". Si observamos otras profesiones -entre las que encontramos tanto a personas clasificadas como indios, negros o pardos, como a blancos-, siendo conscientes de que se trata, en general, de profesiones con menor estatus social ya que implican un menor capital económico, las proporciones de quienes son reconocidos con el "Don" se invierten. Tomando como ejemplo 
el oficio de zapatero -entre quienes se encuentran cinco indios, un negro, un pardo y quince blancos-, observamos que, de aquellas quince personas, sólo seis son agraciadas con el "Don" por el empadronador, excluyendo incluso a un hombre nacido en Londres.

Esta tendencia se mantiene en las profesiones de albañil y carrero: entre los primeros encontramos un negro, un pardo, un indio y siete blancos, a ninguno de los cuales se les otorga el "Don", incluso habiendo entre ellos dos españoles de nacimiento. Entre los carreros, donde se observan cuatro indios, tres negros y veinticuatro blancos, sólo a once blancos se les otorga el "Don".

Podrían estar operando estos factores contextuales al momento en que el empadronador registra, por ejemplo, como blanco a un afromestizo con una profesión de estatus.

\section{Indias e indios}

En el padrón de 1824, Álvarez anota a 422 personas bajo la categoría de indias. Estas representan el 11,5\% de la población total, siendo paranaenses casi la mitad de ellos (44,3\%), y procediendo el resto de Santa Fe (26,5\%), distintos pueblos misioneros $(5,9 \%)$ y otros lugares como Córdoba, Paraguay y Corrientes. La mayoría de los menores de 29 años son nacidos en Paraná, mientras que aquellos que se encuentran en el rango de 30 y 49 años provienen mayoritariamente de Santa Fe. Entre las más longevas, en cambio, se destacan personas provenientes de los pueblos misioneros.

Dado el estrecho vínculo analizado entre la Bajada del Paraná y los pueblos jesuítico-guaraníes, desarrollado a lo largo del siglo XVIII, llama la atención la ausencia -salvo dos casos excepcionales- de apellidos de este origen en el padrón de 1824.

\section{Africanos y afrodescendientes}

Las personas que identificamos como africanas y afrodescendientes en el padrón de 1824 son aquellas a las que el cura Francisco Álvarez clasificó como "negras" y "pardas", quedando afuera de nuestro análisis puntual aquellas personas descendientes de africanas y africanos que fueron eventualmente clasificadas como "indias" o "blancas". ${ }^{15}$ Podemos preguntarnos por qué Álvarez utilizó la categoría "pardo" para empadronar a la población afromestiza. Como observamos, esta categoría gozaba de un amplio uso local desde el siglo XVIII, a lo cual podemos sumar que también era utilizada en su Buenos Aires natal durante las primeras décadas del siglo XIX. Allí, Rebagliati (2014) advierte que por entonces se utilizó este término para referir incluso a personas que habían sido clasificadas como mulatas durante el siglo anterior.

Se registraron 626 pardos y 179 negros, que componen respectivamente un $17,2 \%$ y un $4,9 \%$ del total del padrón. De estas cifras podemos desglosar algunos valores que nos aportan información sobre las características del sector africano y afrodescendiente.

El alto porcentaje de personas oriundas de la ciudad de Santa Fe al cual referimos en párrafos anteriores, se refleja con mayor énfasis entre la población parda. El censista anota a 298 personas como pardos santafesinos; es decir, un $47,5 \%$, contra un $38,3 \%$ de pardos nacidos en Paraná. Si analizamos los rangos etarios de aquellas personas, observamos que este mayor porcentaje
15. A lo largo del padrón, son numerosos los casos donde la descendencia de parejas conformadas por una persona de ascendencia africana -"negro" o "pardo"- y otra que no poseería dicho origen -"blanco" o "indio"- es clasificada directamente como "blanca" o "india". Dichas personas, a pesar de poseer una madre "parda", son consideradas como "blanca" o "india" en las estadísticas que exponemos. 
16. La referencia al origen "portugués" de las personas merece una mención particular: Hacia el siglo XIX, a partir de un proceso de extensión de la "naçao", donde jugó un rol importante la ascendencia de las personas involucradas, se abrieron las puertas a que bajo la denominación de "portugueses" se englobara a personas que podrían ser del Portugal ibérico, del Brasil, de Angola, de Mozambique, o incluso de la India o China (Zeuske, 2017). A su vez, dada la fuerte dinámica migratoria existente entre las fronteras rioplatenses durante el período estudiado, se optó por no considerar a las personas empadronadas como del "Portugal" dentro del conjunto de origen africano. de santafesinos se expresa entre quienes poseen edades mayores a diez años (Figura 4), mientras que la población parda más joven nació mayoritariamente en Paraná.

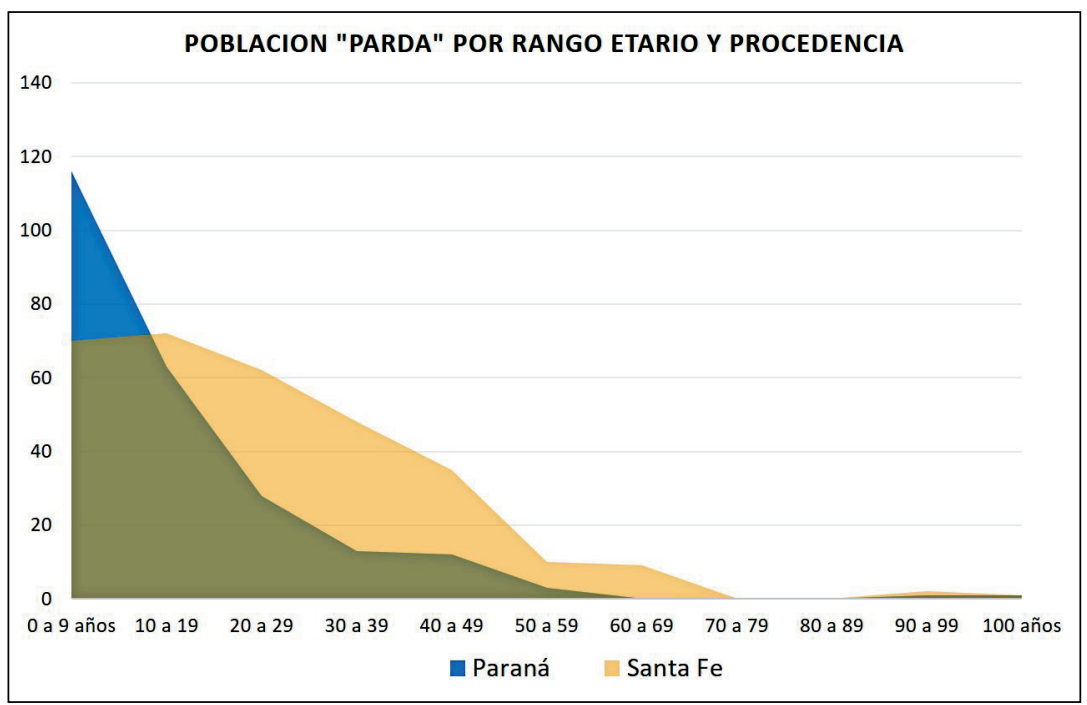

Figura 4. Población parda según rango etario y origen según el censo de Paraná, año 1824.

La población clasificada como negra posee dos orígenes principales: el continente africano y Paraná. El 53,9\% proviene de distintos puntos de África, mientras que un 22,2\% es nacido en Paraná. En tanto, aquellos nacidos en Santa Fe componen un 6,6\%. El resto proviene de Buenos Aires y de "Portugal". ${ }^{16}$

Si consideramos los rangos etarios de quienes nacieron en Paraná, quienes proceden de Santa Fe y de los distintos puntos de África (figura 5), observamos algunas tendencias:

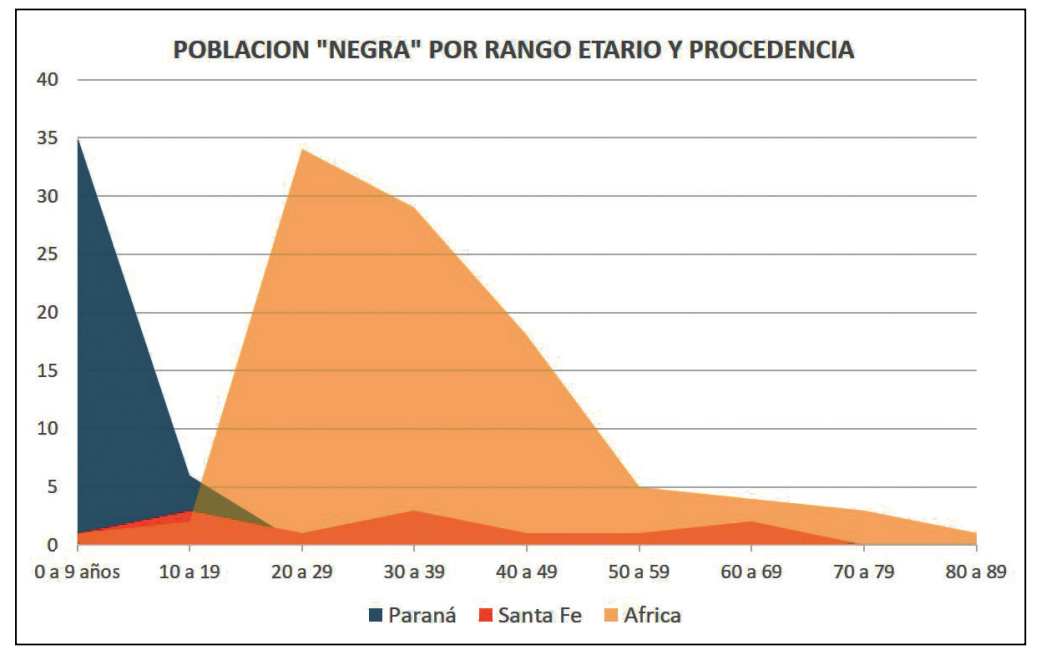

Figura 5. Población negra según rango etario y procedencia según censo de Paraná, año 1824. 
Para comenzar se advierte que, al igual que sucede con la población parda, quienes se encuentran dentro del rango de menor edad -menores a diez añosson mayoritariamente paranaenses. Es notable la baja presencia de personas empadronadas como negros nacidos en Paraná de edades mayores: sólo se registran seis personas de entre 10 y 19 años de edad, dos entre 30 y 39 años y una entre 40 y 49 años. Las personas de origen santafesino, más allá de presentarse en número reducido, mantienen una representación constante en los rangos etarios entre 0 y 69 años de edad.

La población de origen africano, aunque representada en todo el rango -0-89 años- presenta valores más elevados entre los 20 y 49 años de edad. Estos datos aportan información útil para analizar los distintos elementos y características de la trata transatlántica y el arribo de esclavizados al litoral entre fines del siglo XVIII y comienzos del XIX.

Haciendo foco sobre aquellas personas de origen africano, observamos que se empadronó a dos personas como "moros" mientras que entre los lugares de origen encontramos a Angola, Congo, Mina, Benguela, Mozambique y La Costa, y la categoría más amplia de "África", siendo los cuatro primeros los más recurrentes. A grandes rasgos podemos decir que, al momento de realizarse el censo, la mayor cantidad de personas de Angola, Mina y Benguela tienen entre 20 y 29 años, mientras que aquellas empadronadas como procedentes del Congo poseen en su mayoría entre 30 y 39 años de edad. ${ }^{17}$

Al diferenciar entre hombres y mujeres notamos una leve minoría de estas últimas: un $48,6 \%$ de mujeres catalogadas como negras, entre las que se encuentran 44 bozales y 39 criollas. ${ }^{18}$ Entre los hombres, que constituyen el 51,4\% de la población negra empadronada, esta última relación bozales-criollos se ve acentuada: 57 bozales y 27 criollos, lo que se traduce en un $67,8 \%$ y un $12,2 \%$ respectivamente. En cuanto al sector afromestizo se observa que la relación hombre-mujer se invierte, contabilizando un $41,1 \%$ de hombres frente a un $58,9 \%$ de mujeres.

\section{Esclavizadas y esclavizados}

El padrón estudiado presenta una particularidad asociada al momento en que fue confeccionado. Habían pasado poco más de dos años del dictamen del Estatuto Provisorio Constitucional por parte de Entre Ríos, donde se reconocieron y ratificaron las resoluciones de la Asamblea de 1813 en cuanto a la llamada "libertad de vientres", que otorgaba la libertad a aquellos hijos de esclavas nacidos a partir del 31 de enero de 1813. A raíz de esto, según Pérez Colman (1946), encontramos que el número de esclavizados disminuye fuertemente entre lo consignado en los padrones de 1820 y 1824. Por ejemplo, en el primero se registraron 221 esclavos, mientras que cuatro años más tarde encontramos solamente 34 personas esclavizadas. Aunque hacen falta estudios integrales que incluyan reconstrucciones genealógicas y el análisis de ambos censos para definir si lo planteado por Pérez Colman se condice enteramente con lo sucedido, o si existieron además otros factores en juego, consideramos importante analizar quiénes son los esclavizados empadronados en 1824, y cuáles son las características generales de este sector de la sociedad paranaense como un primer aporte en torno a lo planteado.

Se trata de 17 hombres y 17 mujeres de diversos orígenes: Paraná (7), Santa Fe (6), “África” (2), Mina (1), Angola (9), Congo (1), Mozambique (1), Montevideo (1), Buenos Aires (2), Portugal (3) y "Moro" (1). De ellas 13 son nacidas en
17. Exponemos estos datos con la intención de difundir la información brindada por las fuentes, teniendo en cuenta que los mencionados "lugares de origen" hacen referencia más bien a los puertos de embarque de esclavizados en el continente africano, y que los nombres de naciones consignadas en los documentos son el resultado del sistema clasificatorio construido durante el proceso de esclavización y comercialización (Aladrén, 2012).

18. Por razones ya expuestas, no se tuvieron en cuenta aquí a aquellas empadronadas como de "Portugal”, ya que estas podrían haber nacido tanto en África como en el Brasil. En el padrón estudiado se han anotado personas "blancas" y "pardas" oriundas del Portugal, lo cual con mayor seguridad en el caso de los pardos alimenta la hipótesis de que, al menos, parte de los portugueses empadronados vengan desde el Brasil. 
19. AAP. Nuestra Señora del Rosario, Paraná, Bautismos, Libro 4, f. $221 \mathrm{v}$.

20. AAP. Nuestra Señora del Rosario, Paraná, Defunciones, Libro 4, f. 294; y Libro 5, f. 164v.
África, por lo que podemos inferir que 44 de los 57 africanos empadronados eran libres hacia el año 1824.

Si diferenciamos entre nacidos en América y África encontramos una marcada diferencia en torno a las edades de los individuos, algo que estaría relacionado a la prohibición del tráfico atlántico desde 1812: mientras los criollos presentan una edad media de 18,6 años, los africanos presentan una media de 42,8 años. Como un caso particular, se destaca el de Martina Chaparro, empadronada como negra esclava paranaense de nueve años de edad. Sin embargo, Martina nació el 11 de noviembre de $1813,{ }^{19}$ motivo por el cual debería haber sido contemplada como liberta. En el acta de defunción de su hija Justa, párvula, en 1836, es referida como "morena libre o liberta", y una década después ante la defunción de otro hijo suyo llamado Raymundo, en 1846, no se hace ninguna referencia a su condición de liberta. ${ }^{20}$ Este caso se constituye en un ejemplo del carácter multifacético de las primeras legislaciones en torno a la esclavitud y las diversas formas en que se aplicaron en el cotidiano (Crespi, 2011; Candioti, 2017).

\section{Algunas conclusiones}

La sociedad paranaense del siglo XVIII se caracterizó por poseer una alta heterogeneidad étnica, producto de haberse desarrollado en un dinámico espacio fronterizo. Observamos que grandes porcentajes de la población africana, afromestiza e indígena, se asentaron en el poblado paranaense como resultado de procesos migratorios motivados tanto por factores económicos, como por las oportunidades de ascenso social que ofrecía un espacio de poblamiento reciente y consecuentemente marginal a la estructura del gobierno colonial. La movilidad geográfica se ve ejemplificada por las migraciones de sectores afromestizos santafesinos y de personas de ascendencia guaraní procedentes de los pueblos jesuíticos-guaraní.

El área en estudio, como sector de colonización tardía, presenta sus particularidades en cuanto al uso de diversas categorías socio-étnicas. Siguiendo la hipótesis halperiniana sostenemos que en este Nuevo Litoral no habría llegado a cuajar el sistema de castas y, por ende, las barreras raciales se vieron debilitadas en esta región (Farberman y Ratto, 2009; Farberman, 2016). De lo observado en las fuentes trabajadas se desprende la utilización generalizada de la categoría "pardo" para referir a las personas afromestizas durante el siglo XVIII, así como la inexistencia de diversas categorías híbridas propias del llamado sistema de castas.

Tanto las uniones mixtas celebradas entre afrodescendientes e indígenas, como aquellas ocurridas entre guaraníes e indígenas de otros grupos étnicos locales, dibujan un contexto social muy dinámico, que dio origen a la compleja sociedad paranaense del siguiente siglo. De este modo, a comienzos del siglo XIX se destaca una importante población afromestiza representada en mayor medida por quienes habitaban el Barrio del Tambor sobre el sector norte del poblado. En aquel barrio humilde y marginal se alzó el segundo edificio religioso de la ciudad hacia 1822, no con la intención de atraer a la feligresía africana y afromestiza sino con la de contenerla dentro del culto católico. Los recursos puestos en la construcción del templo de ladrillos, constituido en uno de los primeros esbozos de arquitectura Neoclásica en el litoral (Schávelzon, 2017), abre las puertas para considerar esta hipótesis. 
Por último, planteamos que tras estos trabajos preliminares se abren nuevos horizontes investigativos que podrían hacer foco sobre las características particulares de la región estudiada, sistematizando y ahondando tanto en los documentos trabajados hasta el momento como en otra documentación disponible -fondos judiciales, libros de defunciones, testamentarias- en Paraná y Santa Fe.

En este sentido, la inclusión de nuevos fondos documentales se torna crucial al momento de continuar analizando las categorías socio-étnicas empleadas localmente y las relaciones de poder, económicas, genealógicas y de género, imperantes tanto entre los diferentes sectores de la sociedad como dentro de ellos.

\section{Agradecimientos}

A la Dra. Lorena Rodríguez por su orientación en el trabajo documental, al Dr. Daniel Schávelzon por su devolución tras la lectura de este trabajo y a la Dra. Magdalena Candioti por la lectura crítica de un primer manuscrito y sus aportes en torno a la comprensión de la dinámica litoral. A Celia Godoy del AAP por su predisposición. A los/as revisores anónimos por sus observaciones y aportes en torno al trabajo presentado. 


\section{Fuentes documentales citadas}

»Departamento de Estudios Etnográficos y Coloniales, Santa Fe (DEEC). Expedientes Civiles, Tomo 57, Exp. 98.

»Archivo General de la Provincia de Santa Fe (AGPSF). Actas Capitulares, tomo X, f. 114.

» Archivo del Arzobispado de Paraná (AAP). Nuestra Señora del Rosario, Paraná. Bautismos, Libros 1, 2, 3, 4. Paraná, Matrimonios, Libros 1, 2, 3.

»Archivo General de la Nación, Argentina (AGNA). Leg. 9, Exp. 11.

»Archivo General de la Provincia de Entre Ríos (AGPER). Fondo de Gobierno, Serie VII, Leg. 2. 


\section{Q Bibliografía citada}

" Aladrén, G. (2012). “Sem respeitar fé nem tratados: escravidão e guerra na formaçaõ histórica da frontera sul do Brasil (Río Grande de São Pedro, c. 1777-1835)”. Tesis de Doctorado. Universidad Federal Fluminense, Instituto de Ciências Humanas e Filosofia, Departamento de História.

»Areces, N. y G. Tarragó (1999). “Encomiendas y vecinos: estrategias y transgresiones” en Areces, N. (comp.), Poder y Sociedad. Santa Fe la Vieja 1573-1660: 77-98. Rosario, Prohistoria y Manuel Suarez.

»Areces, N. y G. Tarragó (2001). “Familia y negocios: el caso de los Vera Mujica” en Noejovich H. (ed.), América bajo los Austrias: economía, cultura y sociedad: 335 354. Lima, Pontificia Universidad Católica del Perú y Fondo Editorial.

»Areces, N., López, S. y E. Regis (1992). “Relaciones interétnicas en Santa Fe la Vieja: Rescate con charrúas” en Areces, N. (ed.), Reflexiones sobre el V Centenario: 55-69. Rosario, Facultad de Humanidades y Artes Editora - Universidad Nacional de Rosario.

» Areces, N.; López, S.; Regis, E. y G. Tarragó (1999). “Las tierras de la “otra banda”. Los charrúas y los vecinos santafesinos” en Areces, N. (comp.), Poder y Sociedad. Santa Fe la Vieja 1573-166: 131-148. Rosario, Prohistoria y Manuel Suarez.

»Barriera, D. G. (2013). Abrir puertas a la tierra: Microanálisis de la construcción de un espacio político. Santa Fe, 1573-1640. Santa Fe, Ministerio de Innovación y Cultura de la Provincia de Santa Fe: Museo Histórico Provincial Brigadier Estanislao López.

" Boixadós, R. y J. Farberman (2009). “Clasificaciones mestizas. Una aproximación a la diversidad étnica y social en Los Llanos riojanos del siglo XVIII” en Farberman, J. y S. Ratto (coords.), Historias Mestizas en el Tucumán colonial y las pampas (siglos XVII-XIX): 79-114. Buenos Aires, Biblos.

"Calvo, L. M. (1993). La Compañía de Jesús en Santa Fe. La ocupación del espacio urbano y rural durante el dominio hispánico. Santa Fe, Ediciones Culturales Santafesinas.

»Calvo, L. M. (2001). Los Vera Muxica en Santa Fe. Santa Fe, Fundación Rafael del Pino.

»Calvo, L. M. (2004). Santa Fe la vieja entre 1573-1660. La construcción de una ciudad hispanoamericana. Santa Fe, Ediciones UNL.

»Candioti, M. (2016). "Hacia una historia de la esclavitud y su abolición en la ciudad de Santa Fe, 1810-1853" en Guzmán, F.; Geler, L. y A. Frigerio (eds.), Cartografías Afrolatinoamericanas. Perspectivas Situadas desde la Argentina: 99-122. Buenos Aires, Biblos.

»Candioti, M. (2017). "Manumisiones negociadas y libertades frágiles en el Río de la Plata. Santa Fe, 1810-1853" en Freire J. \& M. V. Secreto (comps.), Formas de liberdades: autonomías escravasna América nos séculos XVIII e XIX. Rio de Janeiro, Mauad Editora. (En prensa).

»Carrara, M, (1998). Indígenas y africanos en Santa Fe la Vieja. Revista América, 14: 121-128.

»Ceruti, C. N. (2002). Techos, paredes y pisos. Elementos para el estudio de las técnicas constructivas en Santa Fe y Entre Ríos. Arqueología Histórica Argentina. Actas del 1er Congreso Nacional de Arqueología Histórica: 755-767. Buenos Aires, Corregidor.

»Ceruti, C. N. (2007). “Investigaciones histórico-arqueológicas en torno a la "capilla vieja de San Miguel Arcángel” Paraná (Provincia de Entre Ríos)” en Oliva, F., de Grandis, N. y J. Rodríguez (eds.), Arqueología Argentina en los inicios de un nuevo siglo 1: 385-395. Rosario, Universidad Nacional de Rosario. 
»Cervera, M. (1982). Historia de la ciudad y provincia de Santa Fe (1573-1853). Santa Fe, Editorial UNL.

" Crespi, L. (2011). “Esclavos, libres y libertos en el Río de la Plata. Un lento acceso a la ciudadanía” en Pineau, M. (ed.), La Ruta del Esclavo en el Río de la Plata. Aportes para el Diálogo Intercultural: 187-204. Tres de Febrero, Eduntref.

»Djenderedjian, J. (2008). Límites de casta y nuevos espacios de poder en la frontera. La sedición indígena de 1785 en Entre Ríos y un intento de interpretación. Anuario del CEIC 4: 78-99.

» Farberman, J. (2016). “Imaginarios sociales en la colonia tardía. Clasificaciones y jerarquías del color en Los Llanos de La Rioja, siglos XVIII y XIX” en Guzmán, F. Geler, L. y A. Frigerio (eds.), Cartografías Afrolatinoamericanas. Perspectivas Situadas desde la Argentina: 25-50. Buenos Aires, Biblos.

» Farberman, J. y S. Ratto (2009). “Introducción” en Farberman, J. \& S. Ratto (coords.), Historias Mestizas en el Tucumán colonial y las pampas (siglos XVII-XIX): 9-47. Buenos Aires, Biblos.

»Fasolino, N. (1960). “De la Parroquia de la bajada a la Metropolitana de Paraná”. Conferencia pronunciada por el Excmo. V Rmo. Sr. Dr. Nicolás Fasolino en solemne acto académico. Teatro 3 de febrero de Paraná, año 1887. Buenos Aires.

» Guzmán, F. (1997). Familias de los esclavos en La Rioja tardocolonial (1760-1810). Andes. Antropología e Historia 8: 225-242.

" Guzmán, F. (1999). “De colores y matices: los claroscuros del mestizaje” en Mata de López, S. (comp.), Perspectivas y cambios: Salta y el Noroeste Argentino, 1770-1840: 39-58. Rosario, Prohistoria.

» Guzmán, F. (2011). “Negros, indios y afromestizos en el Tucumán colonial. Una aproximación a las identidades étnicas y al diálogo intercultural” en Pineau, M. (ed.), La ruta del esclavo en el Río de la Plata: 223-239. Caseros, Editorial de la Universidad Nacional de Tres de Febrero.

" Guzmán, F. (2013). "Performatividad social y (sub)categorías coloniales. Mulatos, pardos, mestizos y criollos en tiempos de cambios, guerra y política, en el interior de la Argentina” en Guzmán, F.; Geler, L. y A. Frigerio (eds.), Cartografías Afrolatinoamericanas. Perspectivas Situadas Para Análisis Transfronterizos: 57-83. Buenos Aires, Biblos.

» Guzmán, F. (2016). Los claroscuros del mestizaje. Negros, indios y castas en la Catamarca Colonial. Córdoba, Encuentro Grupo Editor.

» Harman, A. (2010). Los Rostros Invisibles de Nuestra Historia: Indígenas y Africanos en Concepción del Uruguay. Entre Ríos, Editorial Universidad Autónoma de Entre Ríos- Honorable Cámara de Senadores.

» Halperín Donghi, T. (1972). Revolución y guerra. Formación de una elite dirigente en la Argentina criolla. Buenos Aires, Siglo XXI.

» INDEC, 2018. Disponible en Internet: https://www.indec.gov.ar/comunidadeducativa/ tipos_de_piramides.pdf Consultado el 13 de enero 2018.

» Lucaioli, C. (2015). Guerra y persuasión en las fronteras de Santa Fe: la gestión de Francisco Antonio de Vera Mujica (1743-1766). Memoria Americana. Cuadernos de Etnohistoria 23(1): 99-128.

» Lucaioli, C. y S.Latini (2014). Fronteras permeables: circulación de cautivos en el espacio santafesino. RUNA 35 (1): 113-132.

»Latini, S. (2012). Relatos del conflicto interétnico: Francisco García de Piedrabuena contra los “charrúas y otros infieles”, 1715. Corpus. Archivos virtuales de la alteridad ame- 
ricana 2 (2). Disponible en internet: http://ppct.caicyt.gov.ar/index.php/corpus/article/ download/1670/1749. Consultado el 5 de mayo de 2018.

"Latini, S. y C. Lucaioli (2014). Las tramas de la interacción colonial en el Chaco y la otra banda: una campaña punitiva de principios del siglo XVIII. Revista de ciencias sociales, segunda época 26: 7-27. Quilmes.

» Maeder, E. J. y A. S. Bolsi (1982). La población guaraní de la provincia de Misiones en la época post jesuítica (1768-1810). Folia Histórica del Nordeste 5: 60-106.

»Pérez Colman, C. B. (1930). La parroquia y ciudad de Paraná en su segundo centenario, 1730-1930. Paraná, La Acción.

» Pérez Colman, C. B. (1937). Historia de Entre Ríos. Época Colonial (1520-1810). Paraná, Imprenta de la Provincia.

»Pérez Colman, C. B. (1946). Paraná, 1810-1860. Los primeros cincuenta años de la vida nacional. Rosario, Ed. del Autor.

" Rebagliati, L. (2014). Negros y mulatos pobres en Buenos Aires (1786-1821). Quinto Sol 18 (1): 1-22.

" Reina, R. (1973). Paraná; Social Boundaries in an Argentine City. Austin, Institute of Latin American Studies, Universidad de Texas.

"Richard, A. (2015). "Cotidianeidad y etnogénesis en la cuenca media del Arroyo Las Conchas (Dpto. Paraná, Prov. de Entre Ríos) hacia el siglo XVII". Tesina de grado de la carrera de Arqueología, Facultad de Ciencias Naturales e IML, Universidad Nacional de Tucumán.

"Salas, A. (2012). Natalidad y bautismos en Baradero (1756-1765). Épocas. Revista de Historia 6: 37-56.

"Sallaberry, J. (1926). Los charrúas y Santa Fe. Montevideo, Gómez y Cia.

"Schávelzon, D. (2003). Buenos Aires Negra. Arqueología Histórica de una ciudad silenciada. Buenos Aires, Emecé Editores.

》Schávelzon, D. (2017). “¿Arquitectura afro-católica?: La capilla de San Miguel Arcángel en Paraná, Argentina (1824-1836)". Trabajo presentado durante el ciclo Arqueología afrolatinoamericana. Afro-Latin American Research Institute at the Hutchins Center, Harvard University. 15 de septiembre.

"Sors, O. (1981). Paraná: dos siglos y cuarto de su evolución urbana, 1730-1955. Paraná, Colmegna.

"Suarez, T. (1992). "Sexualidad y sociedad en la colonia marginal: Santa Fe, 1860-1780". Tesis de doctorado en Historia, Facultad de Humanidades y Ciencias de la Educación, Universidad Nacional de La Plata.

"Valenzuela, F. (2016). "Dicotomías en las relaciones de esclavizados y descendientes libres en el espacio correntino. Una mirada a la ciudad y campaña, 1770-1820" en Guzmán, F.; Geler, L. y A. Frigerio (eds.), Cartografías afrolatinoamericanas. Perspectivas situadas desde la Argentina: 51-73. Buenos Aires, Biblos.

»Zeuske, M. (2017). "Capitanes y comerciantes catalanes de esclavos" en Rodrigo y Alharilla, M. y L. Chaviano Pérez (eds.), Negreros y esclavos. Barcelona y la esclavitud atlántica (siglos XVI-XIX): 63-100. Barcelona, Icaria. 